\title{
CRIANÇA NEGRA NA EDUCAÇÃO PAULISTA
}

Ivonete Aparecida Alves, Rosiane de Fátima Ponce.

Universidade Estadual Paulista - UNESP, Programa de Pós-Graduação em Educação, Presidente Prudente, SP. E-mail: ivoneteambiente@gmail.com. CAPES - Coordenação de Aperfeiçoamento de Pessoal de Nível Superior

\section{RESUMO}

Esta pesquisa foi gestada a partir de algumas perguntas suleadoras: "O que as pesquisas acadêmicas dos Programas de Pós-Graduação em Educação (PPGEs) do Estado de São Paulo revelam sobre as práticas educativas racistas e antirracistas na Educação Infantil?" e "Quais eixos sobre Educação das Relações Étnicas e Raciais Negras (RERN) podem ser mais relevantes na luta antirracista?". Como questão subsidiária elaborou-se um capítulo para responder à existência de uma história e historiografia da educação da criança negra. Para responder a estas questões foi realizado um estudo de cunho bibliográfico da produção de dissertações e teses da Unesp de Marília, de Presidente Prudente, de Rio Claro, e Araraquara - Educação Escolar; na Faculdade de Educação da USP; na Faculdade de Educação da UNICAMP e na Faculdade de Educação da UFSCar. Palavras-Chave: Educação Infantil; Relações Étnicas e Raciais Negras; Estudo Bibliográfico; Afrocentricidade; Movimento Negro como Sujeito.

\section{BLACK CHILD IN SÃO PAULO EDUCATION}

\begin{abstract}
This research was related was born from some southing questions: "What do academic researches of the Graduate Sudies Programs in Education (PGPE) of the State of São Paulo reveal on the racist and anti-racist educational practices in Child Education?" and "Which axes on the Education of the Ethnic and Black Racial Relationships (EEBRR) can be more relevant on the anti-racist struggle?". As a subsidiary matter, a chapter was elaborated in order to respond to the existence of a history and historiography of black child's education. To answer those questions a bibliographic study of the dissertation and thesis's production of Unesp in Marília, Presidente Prudente, Rio Claro and Araraquara's campuses has been made - Child Education; in Education College of USP; in Education College of UFSCar.
\end{abstract}

Keywords: Child's Education, Ethnic and Black Racial Relationships, Bibliographic Study, Afrocentricity, Black Movement as Subject. 


\section{INTRODUÇÃO}

A luta antirracista, depois de muito trabalho de negros e não-negros em prol da extinção da escravatura (Santos, 1985; Moura, 2013), viveu no Brasil a instituição de uma política de Estado: o branqueamento ou o mulatismo para "assimilar" negros e negras, no período pós-abolição. É preciso conhecer e refletir sobre as possibilidades de pesquisas que ainda dificultam a assunção da temática, essencialmente nos cursos de formação de professoras (es), que poderia alterar, em curto prazo, a situação aviltante de racismo declarado e sub-reptício ainda existente em escolas públicas em todos os níveis de ensino, essencialmente na Educação Infantil (Cavalleiro, 1998; Brasil, 2006; Santiago, 2014), o que nos levou a elaborar este estudo sistematizado sobre as Relações Étnicas e Raciais Negras (RERN) que avançou qualitativamente com a contribuição de africanos (as) radicados (as) no Brasil, além das pesquisadoras e pesquisadores brasileiros, possibilitando, inclusive que pudéssemos constituir uma História da Educação da Criança Negra no Estado de São Paulo, enquanto estava sendo elaborado o corpus do estudo sistematizado, ou uma pesquisa de campo com o temário etnicorracial.

Um dos mais ardorosos no estabelecimento do campo epistemológico sobre a RERN é o congolês, naturalizado brasileiro Kabengele Munanga:

Para enfrentar e combater a ideologia racista ocidental, um caminho diferente do da negritude é possível. O caminho da recusa: por que combater uma mitologia por uma duplicação - uma sobreposição? Esse outro caminho, excêntrico em relação ao campo mitológico, distancia-se e rompe com o modo de pensamento cuja norma é confundir efeito e causa, resultado e origem, subjetivo e objetivo. É verdade, objetivamente, que os negros colonizados são oprimidos na sua cor porque o são como indivíduos e povos. Mas o erro, mitológico, é afirmar a opressão por causa de uma raça. Os negros não foram colonizados porque são negros; ao contrário, na tomada de suas terras e na expropriação de sua força de trabalho, com vista à expansão colonial, é que se tornam pretos. Se existe um complexo de inferiorização do negro, ele é consequência de um duplo processo: inferiorização econômica antes, epidermização dela em seguida (MUNANGA, 2012, p. 81).

Munanga (2012) é objetivo e vai ao ponto, pois a negrura foi instituída para servir a um processo de exploração e a seguir, por escolha política-ideológica houve a adoção de ser negras e negros na luta antirracista e contra todas as opressões. Mas a inferiorização de negras (os) não é econômica somente, é cultural, é educacional, tem um recorte de gênero, de uma complexidade extrema, exigindo esforços de superação impensáveis em outra época, pois as bases epistemológicas (Moore, 2007) para combater o racismo foram constituindo-se historicamente e após os anos 2000, divulgadas de forma sistematizada.

\section{METODOLOGIA}

Este estudo de cunho bibliográfico da produção de dissertações e teses da Unesp de Marília, de Presidente Prudente, de Rio Claro, e Araraquara - Educação Escolar; na Faculdade de Educação da USP; na Faculdade de Educação da UNICAMP e na Faculdade de Educação da UFSCar: sete PPGEs de quatro instituições de ensino público de São Paulo, considerou 192 trabalhos que tratam das RERN em um universo total de 6.873 dissertações e teses defendidas em 14 anos de produção acadêmica na Pós-Graduação em Educação (2000 a 2014). As análises procedidas das dissertações e teses identificadas no processo de estudo, tiveram como contributo fundamental a tônica afroperspectivista: conjunto de pontos de vista, estratégias, sistemas e modos de pensar e viver de matrizes africanas; gestada pelo Movimento Negro no Brasil e na diáspora negra, como 
sujeito político da Educação Popular, além da inspiração da filosofia ubuntu (uma pessoa só é uma pessoa através de outras pessoas). O estudo cíclico levou também em consideração a história de vida da pesquisadora, que entende a militância como importante estratégia de combate ao racismo, comparecendo a experiência vivida como malunga em um mocambo, que perpassa a narrativa na dissertação.

$\mathrm{Na}$ constituição da pesquisa constatou-se que o ano de 2000 foi um marco na produção acadêmico-científica sobre as relações étnicas e raciais negras, com a realização do I Congresso Brasileiro de Pesquisadores (as) Negros (as) (COPENE) que, no ano de $2017^{1}$, chegou à nona edição. Outros trabalhos tinham já realizado pesquisas tratando sobre o temário, compilando dados de período menores ou com recortes, sem buscar os trabalhos em todos os Programas de Pós-Graduação em Educação (REGIS, 2009; MANGUEIRA, 2014; SILVA, 2010). Ora o recorte foi as Ações Afirmativas, ora o currículo. Assim, definimos como fato importante e relevante elaborar um levantamento útil para pesquisadoras e pesquisadores que possam vir a debruçar-se sobre o temário, abarcando um período maior de tempo, permitindo que os próximos levantamentos tenham uma data importante como o final e início de um século como data inicial.

O movimento negro brasileiro tem se destacado na história do nosso país como o sujeito político cujas reivindicações conseguiram, a partir do ano 2000, influenciar o governo brasileiro e os seus principais órgãos de pesquisa, tais como, o Instituto de Pesquisas Econômicas Aplicadas (IPEA), e o Instituto Brasileiro de Geografia e Estatística (IBGE). Este reconhecimento político tem possibilitado, nos últimos anos, uma mudança dentro de vários setores do governo e, sobretudo, nas universidades públicas, como, por exemplo, o processo de implementação de políticas e práticas de ações afirmativas voltadas para a população negra (GOMES, 2011, p.134).

Por estes fatores optamos pela data inicial do levantamento bibliográfico a partir do ano 2000. Ao final destas várias etapas de trabalho, o foco para análise esteve naquelas dissertações e teses que abordaram a Educação Infantil (crianças ou educadoras de crianças de zero a seis anos), com o recorte da proposta da dissertação para analisar os trabalhos sobre Educação Infantil dentro do temário das Relações Étnicas e Raciais Negras. Em um primeiro momento, o termo "criança" foi utilizado como central para a seleção dentro os 192, então obtivemos 22 trabalhos. $\mathrm{Na}$ leitura integral do texto constatamos que o termo "criança" foi utilizado para identificar também pesquisas de seis a doze anos. Assim, ao verificar a idade foco da pesquisa de zero a seis anos, entre os 22 pré-selecionados, permaneceram 11 trabalhos que de fato, tinham como foco a pesquisa na Educação Infantil.

Para avançar nos estudos sobre relações etnicorraciais negras foram primeiramente selecionadas as dissertações e teses que tratam RERN relativas aos diversos níveis de ensino. Para tanto foram lidos os títulos dos 6.873 (seis mil, oitocentos e setenta e três dissertações e teses) e cerca de 800 resumos do Banco de Dados da Coordenação de Aperfeiçoamento de Pessoal de Nível Superior (CAPES) entre os anos 2000 até 2014. A leitura da resumo foi necessária, pois alguns trabalhos não desvelavam se tratavam ou não das RERN. À seguir foram lidas as introduções e também os referenciais bibliográficos. A etapa seguinte foi a organização em tabelas, contendo nome do trabalho, da autoria da dissertação ou tese, orientação por unidade de ensino, até chegar aos selecionados sobre as relações étnicas e raciais negras na educação. Estas pesquisas perfizeram um conjunto dos 192 trabalhos que contemplam o tema das relações étnicas

\footnotetext{
${ }^{1}$ O IX Congresso Brasileiro de Pesquisadores (as) Negros (as) ocorreu em Dourados/MS de 23 a 28 de janeiro de 2017, na Universidade Estadual do Mato Grosso do Sul (UEMS) com o temário "Novas Fronteiras da Intolerância Racial: velhas práticas de discriminação e novos espaços - universo WEB".
} 
e raciais negras, no geral (educação infantil e relações étnicas e raciais, antirracismo em educação, histórias de vida das (os) professoras (es) negras (os), educação no continente africano, etc.).

\section{DISCUSSÃO}

Para depreender dos próprios trabalhos apresentados as correspondências e os movimentos da pesquisa, alguns eixos foram discutidos e propostos, com a importância central na análise do Movimento Negro organizado, assim como das lutas que reverberaram (ou não) dos movimentos sociais das mulheres negras, da luta por creches para as crianças e mais recentemente da escuta qualitativa das crianças pequenas, através de seus desenhos interpretados e depoimentos registrados nos documentos acadêmicos.

Assim foram definidos os tópicos para compor a dissertação: 1) Pesquisas e pesquisadoras (es) em temas relacionados às relações étnicas e raciais negras (1.1. O lugar de onde falam as pesquisadoras e os pesquisadores; 1.2. O silenciamento sobre o racismo na escola); 2) Professoras e as práticas pedagógicas no combate ao preconceito e ao racismo na creche e na educação Infantil (2.1. Currículo escolar e o combate ao preconceito racial nos documentos oficiais; 2.2. A importância da Formação Continuada nas RERN; 2.3. A maneira como as professoras lidam com as situações de preconceito na escola; 2.4. O tratamento dado às crianças negras na creche e na educação infantil quando comparadas às crianças brancas); 3 ) Percepções das professoras sobre infância e as crianças negras (3.1 A percepção que professoras (es) têm da infância/criança negra (Memórias e Observações das outras histórias negras); 4) $A$ questão do branqueamento que envolve crianças negras, preconceitos e racismo (4.1 A educação infantil e o império da estética branca; 5) Espaço, Território; brincadeiras e brinquedos na Educação Infantil; 5. 1 A padronização das creches e educação infantil (práticas) lógica branca, não pensa a diferença, não pensa na inclusão e 5.2 As literaturas na Educação Infantil: complementação ou contraposição.

O que de mais inédito delinearam todos os trabalhos analisados foi o foco estar na educação antirracista em escolas públicas contribuindo de forma decisiva para que existam novas configurações na Educação Infantil, contemplando a diversidade de professoras e suas formações e a diversidade de crianças e suas constituições. Complementando este foco na pesquisa acadêmica, vários trabalhos buscaram nas legislações mais recentes o apoio para embasar as discussões necessárias para transformar em política pública o que foi proposto, mesmo levando em consideração os conflitos advindos de um processo capitalista massacrador, de superação ainda não vislumbrada.

\section{RESULTADOS}

O levantamento realizado nos Programas de Pós-Graduação no estado de São Paulo foi organizado na Tabela I. 
Tabela 1. Dissertações e Teses e as percentagens dos trabalhos na Pós-Graduação em Educação que tratam da temática das Relações Étnicas e Raciais Negras (RERN) no período de 2000 a 2014 São Paulo (Estado)

\begin{tabular}{|c|c|c|c|}
\hline PROGRAMAS & $\begin{array}{l}\text { DISSERTAÇÕES/ TESES DE } \\
2000 \text { A } 2014 \text { - GERAL }\end{array}$ & $\begin{array}{l}\text { DISSERTAÇÕES/TESES RELAÇÕES ÉTNICAS E } \\
\text { RACIAIS NEGRAS (RERN) }\end{array}$ & $\%$ em cada PPGE \\
\hline UNESP Marília & 789 & 06 & $0,76 \%$ \\
\hline UNESP Pres. Prudente & 250 & 05 & $2,00 \%$ \\
\hline UNESP Rio Claro & 199 & 05 & $2.51 \%$ \\
\hline UNESP Araraquara & 601 & 05 & $0.83 \%$ \\
\hline TOTAL UNESP & 1839 & 21 & $1.14 \%$ \\
\hline UFSCar & 793 & 46 & $5.80 \%$ \\
\hline FEUSP & 2131 & 69 & $3.23 \%$ \\
\hline UNICAMP & 2111 & 56 & $2.65 \%$ \\
\hline & Total geral: 6873 & Total RER: 192 & $2.70 \%$ \\
\hline
\end{tabular}

Fonte: Pesquisa de Campo/2016

Na constituição do corpus para análise das dissertações e teses sobre RERN como o tema das relações étnicas e raciais (como o próprio nome porta) trata de seres no mundo, em lugares específicos, no caso no ambiente escolar, as pesquisas selecionadas são portadoras dessa ambiência e da vida imbricada nas relações intra-escola, pois alguns trabalhos tiveram como foco a formação das educadoras ou das professoras da creche, com inserções no desvelamento das subjetividades das várias profissionais da escola de educação infantil, com raros trabalhos que investigaram as famílias de crianças pequenas negras e de não-negras.

Em determinado estágio do processo de pesquisa, as palavras-chave utilizadas nas pesquisas dos textos selecionados foram agrupadas para indicar quais trabalhos deveriam ser lidos na íntegra. Além da idade foco da pesquisa, as palavras-chave foram decisivas para selecionar aqueles trabalhos com foco na educação infantil de zero a seis anos. São elas: Crianças Negras; Professoras de Educação Infantil; Educação Infantil; Crianças Pequenas Brasileiras; Infâncias; Culturas Infantis; Crianças Pequenininhas Negras; Creche; Educação Infantil; Pré-escolas e Primeira Infância.

Após a leitura dos 22 trabalhos que continham as citadas palavras-chave, verificamos que mesmo quando fizeram parte do percurso histórico sobre a educação da criança negra no Brasil e as relações étnicas e raciais na contemporaneidade, nem sempre a pesquisa estava imersa no passado mais recente. A história e a historiografia da educação da criança negra de maneira organizada como identificamos nos trabalhos foi novidade para nós, então optamos por buscar as dissertações e teses que contribuíram para a elaboração deste temário, trazido para a discussão acadêmica pelo sujeito "Movimento Negro no Brasil".

Assim, foram elaboradas as perguntas para tentar responder no momento da análise do trabalho e verificar se ficaria ou não entre os selecionados para apresentação e posterior análise:

- Trata-se de pesquisa contemporânea ou é sobre a história e/ou historiografia da educação da criança negra? (aquelas dissertações e teses da história e/ou historiografia da educação da criança negra foram alocadas, juntamente com outras para compor um histórico); O trabalho tem como foco, de fato, a educação infantil (de zero a seis anos) e as RERN, ou o termo está no título e nas palavras-chave, mas o trabalho tem outro foco? - Houve intervenção da pesquisadora, com propostas efetivas para a melhoria das relações étnicas e raciais negras nas 
escolas investigadas? - Houve apontamento de continuidade da investigação? - Dentre as pesquisadoras, alguma segue pesquisando sobre o tema, ou foi uma pesquisa pontual no momento da Pós-Graduação? - Dentre as pesquisas, alguma avançou em direção a uma pedagogia afrocentrada?

Ao elaborar e discutir as perguntas, durante o processo de qualificação da dissertação, concluímos que era preciso elaborar um capítulo sobre a História e a Historiografia da Criança Negra no Brasil, já que haviam pistas de algumas especificidades na maneira como as pessoas negras estudaram ou no geral, como narraram suas experiências de não ter conseguido acessar a educação quando eram crianças (CAVALLEIRO, 2003). Não ter estudado na infância marcou as subjetividades de várias famílias negras e o investimento para que as novas gerações permanecessem na escola foi intensificado nas falas de mulheres negras e de demais familiares, como constatou Cavalleiro (2003) em sua tese de doutorado em educação.

Com estas questões o trabalho de pesquisa seguiu constituindo um corpus organizado conforme eram respondidas ou justificadas, diante da impossibilidade das respostas, sem novas pesquisas ou pesquisas mais atualizadas.

Quadro 1. Trabalhos sobre RERN selecionados para análise

\begin{tabular}{|c|c|c|c|c|}
\hline $10 z$ & $\triangleright$ & Inst. & Autoria & Título \\
\hline 1 & 尺 & FEUSP & Lucimar Rosa Dias & $\begin{array}{l}\text { * No fio do horizonte: educadoras da primeira infância e o combate ao } \\
\text { racismo. }\end{array}$ \\
\hline 2 & $\underset{D}{\stackrel{D}{\rho}}$ & FEUSP & Maria da Glória Calado & $\begin{array}{l}\text { *Escola e enfrentamento do racismo: as experiências das professoras } \\
\text { ganhadoras do Prêmio Educar para a Igualdade Racial }\end{array}$ \\
\hline 3 & 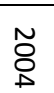 & UFSCar & Fabiana de Oliveira & $\begin{array}{l}* * \text { Um estudo sobre a creche: o que as práticas educativas produzem e } \\
\text { revelam sobre a questão racial? }\end{array}$ \\
\hline 4 & : & UFSCar & Gustavo Martins Piccolo & $\begin{array}{l}\text { **Educação infantil: análise da manifestação social do preconceito na } \\
\text { atividade principal de jogos }\end{array}$ \\
\hline 5 & $\tilde{8}$ & FEUSP & Arlete dos Santos Oliveira & $\begin{array}{l}\text { **Mulheres negras e educadoras - de amas-de-leite a professoras: um } \\
\text { estudo sobre a construção de identidades de mulheres negras na } \\
\text { cidade de São Paulo }\end{array}$ \\
\hline 6 & 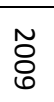 & UFSCar & $\begin{array}{lll}\text { Marisa } & \text { Adriane } & \text { Dulcini } \\
\text { Demarzo } & \end{array}$ & $\begin{array}{l}\text { **Educação das relações étnico-raciais: aprendizagens e experiências } \\
\text { de professoras em São Carlos-SP }\end{array}$ \\
\hline 7 & $\begin{array}{l}\tilde{O} \\
\text { 号 }\end{array}$ & FEUSP & Carolina de Paula Teles & $\begin{array}{l}\text { **Representações sociais sobre as crianças negras na educação } \\
\text { infantil: mudanças e permanências a partir da prática de uma } \\
\text { professora }\end{array}$ \\
\hline 8 & $\underset{\sim}{\stackrel{\sim}{\circ}}$ & UFSCar & Ellen de Lima Sousa & $\begin{array}{l}\text { **Percepções de infância de crianças negras por professoras de } \\
\text { educação infantil. }\end{array}$ \\
\hline 9 & $\underset{\sim}{\stackrel{\sim}{\circ}}$ & FEUSP & Míghian Danae Ferreira Nunes & $\begin{array}{l}\text { **Histórias de Ébano: professoras negras de educação infantil da } \\
\text { cidade de São Paulo }\end{array}$ \\
\hline 10 & $\underset{\omega}{\tilde{\omega}}$ & FEUSP & $\begin{array}{l}\text { Gilmara Aparecida Guedes dos } \\
\text { Santos Dadie }\end{array}$ & $\begin{array}{l}\text { **Personagens negros, protagonistas nos livros da educação infantil: } \\
\text { estudo do acervo de uma escola de educação infantil do município de } \\
\text { São Paulo }\end{array}$ \\
\hline 11 & $\underset{\perp}{\stackrel{O}{\rho}}$ & $\begin{array}{l}\text { UNICAM } \\
\text { P }\end{array}$ & Flávio Santiago & $\begin{array}{l}\text { ** “O meu cabelo é assim... igualzinho o da bruxa, todo armado": } \\
\text { hierarquização e racialização das crianças pequenininhas negras na } \\
\text { educação. }\end{array}$ \\
\hline
\end{tabular}

Fonte: Pesquisa de Campo/2016

*Tese ${ }^{* *}$ Dissertação 


\section{CONCLUSÃO}

Nas análises procedidas para elaborar a dissertação, concluímos que a criança negra esteve fora da historiografia oficial na experiência do curso de pedagogia onde estudamos, assim como em outros cursos de pedagogia discutidos via os trabalhos acadêmicos citados para a elaboração do capítulo sobre a Educação da Criança Negra. O percurso desta educação diferenciada no Estado de São Paulo foi realizado por vários militantes do Movimento Negro entrevistados para elaboração das dissertações e teses pesquisadas, em várias etapas desta pesquisa. A criança negra na educação paulista contemporânea ainda é impactada por vários eventos onde o preconceito é constatado, sem que exista uma assunção efetiva de políticas públicas antirracistas na educação. A sistematização das ações foi assumida por organizações do terceiro setor e alguns grupos de pesquisas que tem a criança como foco, assim como grupos de pesquisas de formação de professoras (es). Assim, a criança como foco de uma educação antirracista, tanto na ótica da negritude como na ótica da branquitude carecem de novas pesquisas, inclusive de pesquisas de cunho etnográfico e também da pesquisa-ação que tenham como objetivo interferir, propor e coordenar ações antirracistas.

\section{REFERÊNCIAS}

CAVALLEIRO, Eliane dos Santos. (1998). Do silêncio do lar ao silêncio escolar: racismo, preconceito e discriminação na educação infantil. 1998. 241 f. Dissertação (Mestrado em Educação) Faculdade de Educação, Universidade de São Paulo.

CAVALLEIRO, Eliane dos Santos. (2003). Veredas das noites sem fim: um estudo com famílias negras de baixa renda sobre o processo de escolarização e a construção do pertencimento racial. 2003. 315 f. Tese (Doutorado em Educação).

FREIRE, Paulo. (2004). À sombra desta mangueira. São Paulo: Olho d'Água.

MOORE, Carlos. (2007). Racismo e sociedade: novas bases epistemológicas para entender o racismo. São Paulo: Mazza.

MOURA, Clóvis. (2013). Dicionário da escravidão negra no Brasil. São Paulo: EDUSP.

MUNANGA, Kabengele. (2012) Negritude: usos e sentidos. Belo Horizonte: Autêntica.

OLIVEIRA, Alda Maria S. de S. (2012). Movimento de luta por creches, Fórum permanente de educação infantil do estado do Rio de Janeiro e Movimento Interfóruns de Educação Infantil do Brasil - resistências, contradições, pactuações e rupturas. Revista Dialogus, Niterói, n. 01, ano 1.

ROSEMBERG, Fulvia. (2011). A criança pequena e o direito à creche no contexto dos debates sobre infância e relações raciais. In.: BENTO, Maria Aparecida da Silva. Educação Infantil, igualdade racial e diversidade: aspectos políticos, jurídicos, conceituais. São Paulo: CEERT, p. 11-46. 